\title{
La lucha contra el terrorismo en la Unión Europea desde una perspectiva procesal ${ }^{1}$
}

\section{The Fight Against Terrorism in the European Union from a Procedural Perspective}

\author{
Ángel Tinoco Pastrana ${ }^{2}$ \\ Universidad de Sevilla (España)
}

Recibido: 16-02-16

Aprobado: 02-04-16

\section{Resumen}

El terrorismo constituye una de las principales amenazas para la seguridad en la Unión Europea, y por tanto para la consolidación del espacio de libertad, seguridad y justicia. La Estrategia de lucha contra el terrorismo de la Unión Europea define su política antiterrorista, partiendo de la compatibilidad de la lucha contra esta amenaza y el respeto de los derechos humanos. La política antiterrorista de la Unión Europea se ha materializado en multitud de instrumentos, disposiciones y actos. El espacio de libertad, seguridad y justicia requiere profundizar en la cooperación judicial y policial en materia penal y en la implantación del principio de reconocimiento mutuo. Destacaremos aquellos instrumentos fundamentados en este principio que son especialmente útiles para la lucha contra el terrorismo, en cuanto a la entrega de personas y obtención de pruebas.

Palabras-clave: política antiterrorista, Unión Europea, cooperación judicial y policial penal, reconocimiento mutuo.

\footnotetext{
${ }^{1}$ El presente estudio se enmarca dentro de la Red de Excelencia sobre "Los actuales desafíos del Derecho Internacional", del Plan Estatal de Investigación Científica y Técnica y de Innovación 20132016 (DER15-69273-RED) y del Proyecto de Investigación "Un paso adelante en la consolidación del espacio judicial europeo y su aplicación práctica en España: visión desde el proceso civil y penal”, Plan Nacional de I+D+I (Ref.: DER2015-71418-P (MINECO/FEDER).

2 (atinoco@us.es) Profesor de Derecho Procesal, Universidad de Sevilla. Autor de Fundamentos del Sistema Judicial Penal en el Common Law (2001), "Le procès pénal devant la Cour Pénale Internationale. Point de Vue Espagnol", Revue Pénitentiaire et de Droit Pénal (2005), "El Estatuto español de la víctima del delito y el derecho a la protección", Processo Penale e Giustizia, G. Giappichelli Editore (2015), y "La protection des victimes de violence domestique et de genre dans la procédure pénale espagnol”, Revue de Science Criminelle et de Droit Pénal Comparé (2015).
} 


\begin{abstract}
Terrorism constitutes one of the main threats to security in the European Union, and thus to consolidate the area of freedom, security and justice. The EU counter-terrorism strategy defines its antiterrorist policy, departing from the compatibility of the fight against this threat and the respect of the humans rights. The antiterrorist policy of the European Union has materialized in multitude of instruments, dispositions and acts. The area of freedom, security and justice requires deepen in the judicial and police cooperation in criminal matters and the implementation of the principle of mutual recognition. We will emphasize those instruments based on this principle that are especially useful in the fight against the terrorism, in relation for the persons' delivery and obtaining evidence.
\end{abstract}

Key-words: antiterrorist policy, European Union, judicial and police cooperation in criminal matters, mutual recognition.

\title{
1. El espacio de libertad, seguridad y justicia en la Unión Europea, la lucha contra el terrorismo y el respeto de los derechos humanos
}

A modo de introducción, vamos a exponer una serie de cuestiones respecto al desarrollo del espacio europeo de libertad, seguridad y justicia, determinados actos adoptados por la Unión Europea (UE) en materia de terrorismo y la dialéctica de la lucha contra este tipo de criminalidad y la protección de los derechos fundamentales. Luego veremos la estrategia antiterrorista de la UE y finalmente trataremos los instrumentos de reconocimiento mutuo específicos para la entrega de personas y obtención de pruebas. Dada la pluralidad de medidas, disposiciones e instituciones que van a ser expuestas, a medida que las desarrollemos iremos incorporando las respectivas valoraciones y conclusiones.

Debemos destacar de forma previa, que como desarrollo del espacio de libertad, seguridad y justicia, existen una pluralidad de instrumentos de cooperación judicial y policial en materia penal, fundamentados en el principio de reconocimiento mutuo y en la armonización del Derecho penal y procesal penal de los Estados de la UE, o bien en la aproximación, la cual como veremos, parece ser que en la actualidad está sustituyendo al anterior objetivo de armonización. Si bien carecemos de un instrumento de reconocimiento mutuo exclusivo para el terrorismo, es indudable la importancia del desarrollo de este principio para la lucha contra estos delitos y sobre todo de determinados instrumentos específicos que trataremos, referentes a la entrega de personas y obtención de pruebas. No obstante los instrumentos de reconocimiento mutuo no constituyen como es obvio las únicas herramientas que en el marco del 
espacio europeo de libertad, seguridad y justicia, son relevantes para la lucha contra el terrorismo. Existen además numerosas instituciones y disposiciones normativas, como veremos. El principio de reconocimiento mutuo constituye la "piedra angular" de la cooperación judicial, permite el reconocimiento automático de resoluciones de otro Estado sin procesos intermedios para su homologación, y parte de un alto grado de confianza entre los Estados 3 .

En la actualidad en el "Programa Justicia 2014-2020"4, se echa en falta una referencia expresa a los delitos de terrorismo, y por tanto a la lucha contra este fenómeno que constituye una de las principales amenazas para la seguridad en la UE, y por ende para el propio espacio de libertad, seguridad y justicia en su integridad. Ello contrasta con su antecesor, el "Programa de Estocolmo Una Europa abierta y segura que sirva y proteja al ciudadano" 5 , que incorpora numerosas referencias al terrorismo desde diversas perspectivas, tales como la prevención, protección, persecución, respuesta y protección a las víctimas. Sin embargo el Programa Justicia 2014-2020 parece estar más preocupado por determinadas formas de criminalidad como el narcotráfico del mismo modo que por el consumo de estupefacientes, dadas las consecuencias económicas que acarrea para los Estados, y por la formación de los Jueces y profesionales o personal al servicio de la Administración de Justicia, que en profundizar en los anteriores objetivos del espacio de libertad, seguridad y justicia.

Por otra parte parece que opta por la aproximación de las legislaciones internas en lugar de por su armonización ${ }^{6}$, como igualmente parece desprenderse de la reciente Directiva 2014/41/CE, relativa a la orden europea de investigación en materia penal (DOEI). Además el Programa Justicia posee fundamentalmente un contenido de carácter económico. En este sentido, la reciente Directiva 2015/849/UE tiene como objeto la prevención del blanqueo de capitales y la financiación del terrorismo, por lo que nuevamente encontramos este planteamiento desde la perspectiva de la estabilidad del sistema financiero. Sin que neguemos importancia a la financiación del terrorismo como una de las principales formas de atajar este problema, no hay que obviar otras importantes acciones que son fundamentales para la lucha contra esta amenaza. Igualmente vemos como la propia Fiscalía Europea, prevista en el TFUE, que se crea a

\footnotetext{
${ }^{3}$ Capítulos 3 a 5, Título V del Tratado de Funcionamiento de la UE (TFUE).

${ }^{4}$ Reglamento (UE) no 1382/2103 del Parlamento Europeo y del Consejo, de 17 de diciembre de 2013, por el que se establece el Programa "Justicia" para el período 2014 a 2020, DOCE n⿳ L 354 de 28/12/2013.

${ }^{5}$ El Consejo Europeo con el "Programa de Estocolmo", estableció un plan de trabajo en la UE para el espacio de libertad, seguridad y justicia, durante el período 2010-2014 (DOCE n ${ }^{\circ} \mathrm{C} 115,4 / 05 / 2010$ ).

6 María Pía Calderón Cuadrado, Contra la armonización positiva -y procesal- en la Unión Europea, [en Andrés de la Oliva Santos y María Pía Calderón Cuadrado, dirs.: La armonización del Derecho Procesal tras el Tratado de Lisboa, Cizur Menor, Thomson Reuters, Aranzadi, 2012], pp. 126 y 127. En el TFUE (artículos 67, 81 y 82) se ha sustituido la expresión clásica “armonización” por “aproximación”, la cual no excluye la heterogeneidad de los ordenamientos jurídicos.
} 
partir de Eurojust ${ }^{7}$, está concebida para proteger los intereses financieros de la Unión, como se desprende del artículo 86.1 TFUE.

Tras los atentados del 11 de septiembre de 2001 en Estados Unidos, el Consejo Europeo se pronunció considerando el terrorismo como un reto global, comprometiéndose a adoptar una postura más sólida en la materia, y estableciendo como un objetivo prioritario de la UE la lucha contra el terrorismo. De hecho se incrementaron significativamente los actos normativos de la UE, dada la necesidad de cooperar con terceros, tanto Estados como organizaciones como la ONU. Observamos una gran variedad de disposiciones e instituciones, como consecuencia por un lado de la complejidad de este fenómeno y por otro dados los "vaivenes" de la política antiterrorista de la UE. Pero es necesario destacar que la actuación de la UE en esta materia es complementaria a la de sus Estados miembros. Éstos son los auténticos protagonistas, redimensionándose dos sectores en los que impera la "lógica intergubernamental", y la UE se desarrolla firmemente en la lucha contra el terrorismo. Por un lado se trata del espacio de libertad, seguridad y justicia (Título V TFUE), en el que adquiere un especial protagonismo en principio de reconocimiento mutuo y la cooperación judicial en materia penal y policial (arts. 81 a 89 TFUE), y por otro lado la Política Exterior y de Seguridad Común. Si bien hacemos referencia a estos dos ámbitos en el TFUE y por tanto tras el Tratado de Lisboa, igualmente eran fundamentales antes de su entrada en vigor. Tampoco se puede comprender la actuación de los Estados sin considerar la UE como entidad de naturaleza política y jurídica ${ }^{8}$.

Pero como veníamos exponiendo, parece ser que la preocupación que existía desde 2001 respecto a la seguridad y la amenaza terrorista, se ha podido ver desplazada en las prioridades de la UE por la crisis económica y la estabilidad del sistema financiero. Es importante destacar que tras los atentados de 2001, encontramos un punto de inicio y/o reflexión en cuanto a la renuncia a los derechos civiles a cambio de seguridad, y por tanto respecto al sacrificio de determinados derechos fundamentales de los ciudadanos para luchar contra la amenaza terrorista, extremo en el que encontramos numerosos ejemplos en diversos ordenamientos internos. Estamos ante una cuestión o debate que aún permanece, en la que los derechos fundamentales de carácter procesal, es decir, aquellos que se restringen en las investigaciones penales y en las medidas cautelares que se puedan adoptar, gozan de un

\footnotetext{
7 Órgano creado en 2002 para incrementar la eficacia de las autoridades nacionales en la persecución e investigación en la UE de las formas graves de delincuencia que afecten a dos o más Estados o deba perseguirse según criterios comunes, regulado en el artículo 85 TFUE y constituido por representantes de cada Estado.

${ }^{8}$ Sobre estas observaciones, Carmela Pérez Bernárdez, El collage de la politica antiterrorista de la Unión Europea, [en Manuel Pérez González, dir., y Elena Conde Pérez, coord.: Lucha contra el terrorismo, Derecho Internacional Humanitario y Derecho Penal Internacional, Valencia, Tirant lo Blanch, 2012], pp. 173 a 177 y 183.
} 
especial protagonismo. De cualquier modo debemos posicionarnos a favor de mantener el equilibrio entre la seguridad y la protección de los derechos humanos, del respecto del Estado de Derecho como un principio inexcusable y un valor. Considerar que sólo se puede proteger efectivamente la seguridad nacional a través de políticas restrictivas de estos derechos, no sólo ha puesto de manifiesto su ineficacia para disminuir los peligros que se procuran evitar sino que incluso los ha incrementado9. Pero como se pone de manifiesto en las recientes reformas en 2015 del Código Penal español (CP) y de la Ley de Enjuiciamiento Criminal (LECRIM), determinados postulados que pueden responder a este planteamiento y por consiguiente al denominado Derecho procesal penal "del enemigo", parecen estar más vigentes que nunca.

Como comentábamos, son los Estados los auténticos protagonistas de la lucha contra el terrorismo en la UE. Por ello la tensión entre libertad y seguridad se multiplica, dadas las diversas sensibilidades de cada Estado miembro. A ello se une que la política antiterrorista requiere de diversos instrumentos y acciones y precisa de una gran coordinación, la cual no siempre da sus frutos, y que los Estados continúan siendo celosos de su soberanía, lo que requiere una gran labor negociadora que a veces resulta estéril, a lo cual se añaden los problemas prácticos derivados de la falta de cooperación ${ }^{10}$. Observamos que además todo ello compromete el desarrollo y por tanto la progresiva implantación del principio de reconocimiento mutuo. Tanto el Derecho penal como el Derecho procesal penal ostentan casi siempre un papel especial en la lucha contra el peligro mundial que supone el terrorismo, siendo consideradas las armas más potentes del Estado. Pero su eficacia está limitada desde el principio por la tradicional vinculación del ius puniendi con los Estados nacionales específicos. Por ello se invocó un importante principio, que sustituye a la tradicional asistencia judicial y policial, el principio de reconocimiento mutuo al que acabamos de referirnos, fundamental para la consolidación del espacio de libertad, seguridad y justicia. Pero este principio es controvertido y numerosos autores han resaltado que reconocer los actos procesales de otros Estados, puede suponer un descenso de los requisitos para limitar los derechos fundamentales nacionales ${ }^{11}$.

Hay que observar que el respeto de los derechos humanos en materia de seguridad y lucha contra el terrorismo, no sólo constituye una preocupación de

\footnotetext{
${ }^{9}$ En este sentido, Milena Costas Trascasas, Seguridad nacional y derechos humanos en la reciente jurisprudencia del Tribunal Europeo de Derechos Humanos (TEDH) en materia de terrorismo internacional: ¿hacia un nuevo equilibrio?, [en Elena Conde Pérez y Sara Iglesias Sánchez, coord.: Terrorismo y legalidad internacional, Madrid, Dykinson, 2012], pp. 187 y 188.

${ }^{10}$ En este sentido, Joaquín Forner Delaygua y Natacha González Viada, La acción de la Unión Europea contra el terrorismo, "Revista de Estudios Europeos", 53 (2009), p. 158, que destacan las dificultades de estas tres características propias de la lucha contra el terrorismo en la UE.

${ }^{11}$ Klaus Tiedemann, El futuro del proceso penal europeo. Aspectos de interés, en especial sobre la lucha antiterrorista, [en Juan-Luis Gómez Colomer y José-Luis González Cussac, coords.: Terrorismo y proceso penal acusatorio, Valencia, Tirant lo blanch, Universitat Jaume-I, 2006], pp. 435, 437 y 438.
} 
los Estados miembros, sino que también la encontramos en la jurisprudencia del Tribunal de Justicia de la Unión Europea (TJUE), respecto a la creación de las listas de "personas, grupos y entidades implicadas en actos de terrorismo", según el sistema "targeted or smart sanctions" (sanciones selectivas o inteligentes), por el que se crea la lista anexa al Reglamento 881/2002, para el bloqueo y la congelación de bienes. Éste junto con el Reglamento 2580/2001, desarrollan en la UE la Resolución ONU 1373, la Posición Común 2001/931 y la Posición Común 2002/402/PESC del Consejo, que establecen el procedimiento para dar efectos en la UE a las listas elaboradas por el Consejo de Seguridad ONU ${ }^{12}$. En la sentencia del TJUE de 3 de septiembre de 2008, asuntos acumulados Kadi y Yusufy Al Barakaat, planteados por la reclamación de los demandantes contra su inclusión en la mencionada lista anexa, se planteó el problema del nivel de protección de los derechos humanos en los supuestos en que la UE "mimetice" normas de otros ordenamientos y del Derecho internacional. El TJUE de forma taxativa, afirma la autonomía del Derecho europeo y que la inclusión en las listas viola el derecho de defensa, de audiencia y el derecho a la tutela judicial efectiva, dada la ausencia de comunicación motivada a los interesados, anulando el Reglamento 881/2002 para los demandantes y rechazando que su jurisdicción esté limitada al tratarse de Resoluciones del Consejo de Seguridad ONU. En definitiva el TJUE pone de manifiesto que es viable compatibilizar la seguridad y defensa y las garantías individuales básicas, y que frente a un Derecho internacional que actúa de forma "tosca" y coloca al individuo en una posición secundaria, el Derecho europeo se fundamenta en valores individuales ${ }^{13}$.

Esta preocupación también es patente en el Tribunal Europeo de Derechos Humanos (TEDH). En el asunto Bosphurus (2005), estableció el criterio de la regla de la "protección equivalente", doctrina según la cual la ejecución en la UE de las resoluciones del Consejo de Seguridad, sólo es conforme al Convenio Europeo de Derechos Humanos (CEDH) si está acompañada de un sistema efectivo de recursos jurisdiccionales, tal y como exige el artículo $6 \mathrm{CEDH}$. En caso contrario el TEDH tendría jurisdicción para examinar la

\footnotetext{
${ }^{12}$ Miguel Revenga Sánchez, Protección multinivel de los derechos fundamentales y lucha contra el terrorismo a escala europea (a propósito de las listas negras y otras anomalías de la Unión), "Revista vasca de Administración Pública", 82 (2008), pp. 243 a 245. A instancias fundamentalmente de Estados Unidos, la ONU ha impulsado tras los atentados de 2001 una política de "sanciones inteligentes", imponiendo obligaciones erga omnes. Este sistema ha sido poco respetuoso con las garantías mínimas que requiere la gravedad de las consecuencias que conlleva estar en estas listas. Además de la falta de publicidad de las razones para la inclusión y de cauces procesales para rebatirlas, las listas han padecido errores garrafales, como consecuencia de las informaciones erróneas de los Estados e incluso de errores derivados de la reproducción de la grafía árabe. La multiplicación de los escenarios de lucha contra el terrorismo debilita o refuerza los compromisos adquiridos a través del reconocimiento interno o internacional de ciertos derechos.

${ }^{13}$ Sobre la mencionada STJUE, Joaquín J. Forner Delaygua y Natacha González Viada, op. cit., pp. 170 a 173 .
} 
legalidad de dicha ejecución, doctrina que resulta de aplicación a los Tribunales garantes de los derechos y libertades fundamentales y por tanto a los Órganos Jurisdiccionales nacionales ${ }^{14}$.

La UE siempre ha preservado la obra del Consejo de Europa, como se puso de manifiesto en la modificación por la Decisión Marco 2008/919/JAI de la Decisión Marco predecesora de 2002, sobre la definición de los delitos de terrorismo, vinculándola al Convenio del Consejo de Europa sobre la Prevención del Terrorismo de 2005. Igualmente el Consejo de Europa es fundamental en la cuestión entre la tensión de la protección de los derechos humanos y la lucha contra el terrorismo, como se puso de manifiesto cuando informó públicamente de actividades ilícitas tales como los "vuelos de la CIA" y las detenciones ilegales ${ }^{15}$. Observamos como a raíz de los asuntos Modjahedines del Pueblo de Irán c. Consejo, el Tribunal de Primera Instancia (TPI) en la sentencia de 12 de diciembre de 2006, reafirmó la necesidad de respetar el respeto del derecho de defensa, la tutela judicial efectiva, la obligación de la motivación al elaborar las listas por los Estados y que es necesario dar audiencia respecto a las pruebas de cargo. Aunque el TPI reconoce que existen limitaciones en materia de terrorismo por razones de seguridad, interés general y eficacia de las sanciones, que pueden afectar o demorar dicha audiencia, ésta no puede excluirse en modo alguno. De hecho en este asunto el TPI tiene en cuenta la jurisprudencia del TEDH, según la cual en asuntos que afecten a la seguridad nacional y en concreto respecto al terrorismo, pueden permitirse ciertas limitaciones del derecho de defensa, especialmente en lo referente a la divulgación de las pruebas de cargo y a las modalidades de acceder a los autos, y que ello no impide el respeto estricto del artículo $6 \mathrm{CEDH}^{16}$. En este sentido, el Consejo de Europa permite que en la lucha contra el terrorismo puedan justificarse ciertas restricciones del derecho de defensa, tales como el abogado de elección propia, el acceso a los autos o que excepcionalmente se admita el testigo anónimo, para preservar la seguridad de agentes o policías. Pero estas restricciones sólo son admisibles si son estrictamente necesarias y al mismo tiempo se establecen medidas compensatorias de las mismas, de tal forma que el proceso en su totalidad cumpla con las garantías del artículo $6 \mathrm{CEDH}^{17}$.

${ }^{14}$ En relación a la doctrina Bosphurus, Francisco Jiménez García, Tutela judicial efectiva, pilares intergubernamentales de la Unión Europea y Naciones Unidas o viceversa. El periplo comunitario marcado por los asuntos Yusuf/Kadi, Ayadi/Hassan, Modjahedines del pueblo de Irán y Segi/gestoras, [en Antonio Cuerda Riezu y Francisco Jiménez García, dirs.: Nuevos desafios del Derecho Penal Internacional. Terrorismo, crimenes internacionales y derechos fundamentales, Madrid, Tecnos, 2009], pp. 426 y 427.

${ }^{15}$ Sobre la actuación del Consejo de Europa, Carmela Pérez Bernárdez, op. cit., pp. 179 y 180.

${ }^{16}$ Respecto al asunto Modjahedines, Francisco Jiménez García, op. cit., pp. 445 y 448.

17 Véase Lorena Bachmaier Winter, Información de inteligencia y proceso penal, [en Lorena Bachmaier Winter, coord.: Terrorismo, proceso penal y derechos fundamentales, Madrid, Marcial Pons, 2012], pp. 99 y 100. Ello se pone de manifiesto en la jurisprudencia del TEDH y en las Guidelineson Human Rights and the Fight against Terrorism, de diciembre de 2002. 
Desde este punto de vista vemos como la reciente reforma de la LECRIM por la LO 13/2015, de fortalecimiento de las garantías procesales y la regulación de las medidas de investigación tecnológicas, permite ciertas restricciones en materia de terrorismo. En concreto se restringe el derecho a designar libremente abogado (artículo 118) y se puede prorrogar la detención o prisión incomunicada por un plazo adicional de cinco días (artículo 509.2). Además se privan al detenido o preso del derecho a comunicarse con otras personas con las que tendría derecho a hacerlo, del derecho a entrevistarse reservadamente con su abogado y a acceder a las actuaciones, lo cual deberá solicitar la policía o el Fiscal al Juez, si bien se entenderá acordado por un plazo máximo de 24 horas en cuanto lo soliciten (artículo 527). Además la intervención de la correspondencia, la interceptación de las comunicaciones telefónicas y telemáticas, el registro remoto sobre equipos informáticos y el registro de dispositivos de almacenamiento masivo es decir, las nuevas diligencias de investigación tecnológicas, están previstas sólo para determinados delitos, entre los que figura el terrorismo (artículo 579.1, entre otros). A ello se une la reciente reforma del $\mathrm{CP}$, que establece un régimen diferente de cumplimiento de la condena en casos de terrorismo, por lo que de alguna forma parece que estamos ante un auténtico Derecho penal y procesal penal "del enemigo".

\section{La estrategia de lucha contra el terrorismo en la Unión Europea}

La compatibilidad entre la lucha contra el terrorismo y el respeto de los derechos humanos, se destaca expresamente en la "Estrategia de lucha contra el terrorismo" (en adelante la Estrategia). Definida por el Consejo Europeo en $2005^{18}$ constituye una de sus políticas y no se limita a combatir el terrorismo en Europa sino que extiende este objetivo a todo el mundo, preservando al mismo tiempo el respeto de los derechos humanos. Esta estrategia pretende crear una Europa segura que permita un espacio de libertad, seguridad y justicia. La Estrategia se fundamenta en cuatro bloques: prevenir, proteger, perseguir y responder. Dada la multitud y diversidad de medidas e instrumentos adoptados en el seno de la UE, vamos a definir y a tratar estos cuatro bloques, sistematizando en la medida de lo posible las medidas e instrumentos referidos, si bien advertimos que dada la transversalidad de algunos de ellos, aunque se puedan ubicar en un bloque específico su eficacia se despliega en otros.

${ }_{18}$ Se trata del Acto del Consejo Europeo de 30 de noviembre de 2005. Como actos conexos a la Estrategia, tenemos el Informe del Consejo de la UE de 17 de enero de 2011, sobre el Plan de acción de la UE para la lucha contra el terrorismo, la Estrategia revisada sobre financiación del terrorismo del Consejo de la UE de 17 de julio de 2008, y la Decisión 2007/124/CE del Consejo de 12 de febrero de 2007, por la que se establece para el período 2007-2013 el programa específico "Prevención, preparación y gestión de las consecuencias del terrorismo y de otros riesgos en materia de seguridad", integrado en el programa general "Seguridad y defensa de las libertades". 
Además destacaremos aquellas instituciones, medidas e instrumentos que son especialmente relevantes desde un punto de vista procesal.

La prevención tiene como finalidad luchar contra la radicalización y captación de terroristas, localizando los métodos, propaganda y herramientas usadas por los terroristas. Ello depende fundamentalmente de los Estados, contribuyendo la UE a coordinar las políticas nacionales, las buenas prácticas y el intercambio de información. En este ámbito goza de un especial protagonismo en la actualidad el control del uso de internet ${ }^{19}$, de gran relevancia para la captación y radicalización. Entre otros instrumentos de la UE, y destacamos por su importancia la Decisión Marco 2006/960/JAI, sobre la simplificación del intercambio de información e inteligencia entre los servicios de seguridad de los Estados miembros de la UE, en el contexto de las investigaciones criminales u operaciones de inteligencia crimina ${ }^{20}$. Tras los atentados de 2001 en Estados Unidos, la separación entre prevención y represión y por tanto entre inteligencia y proceso penal se ha ido diluyendo, fundamentalmente en delitos como el terrorismo. Vemos por tanto como los servicios de inteligencia y las autoridades del proceso penal parece que están avocados a cooperar. Además la obligación de las compañías de telecomunicaciones de archivar las comunicaciones electrónicas, permite acceder a multitud de datos con fines preventivos, siendo necesario determinar en qué medida la información obtenida por los servicios de inteligencia sin estricto control judicial, puede ser utilizada en el proceso penal. Por ello se ha llegado a acuñar en la jurisprudencia española el concepto de "prueba pericial de inteligencia". La Decisión Marco antes referida, permite condicionar la eficacia probatoria de la información de inteligencia transmitida en otro Estado, si el Estado que la remite diera su consentimiento para esta finalidad ${ }^{21}$. En definitiva el intercambio de información entre los servicios de inteligencia goza de una enorme transversalidad en los bloques de la estrategia antiterrorista de la UE, ostentando también gran relevancia para la persecución y por tanto en el ámbito procesal. Lo mismo sucede con las fuentes de financiación, materia que trataremos en la persecución.

${ }^{19}$ La trascendencia de ello se pone de manifiesto en la reciente reforma de la LECRIM por la LO 13/2015, que introduce la figura del "agente encubierto informático", que previa autorización judicial puede intercambiar o enviar archivos ilícitos y analizar los resultados de los algoritmos que los identifican, y que incluso permite que se puedan grabar las imágenes y conversaciones de los encuentros entre el agente y el investigado en el interior de un domicilio (artículo 282 bis.6 y .7). Esta diligencia de investigación está restringida a determinados delitos, entre los que se contempla expresamente el terrorismo.

${ }^{20}$ Incorporada al Derecho español por la Ley 31/2010, de 27 de julio, sobre simplificación del intercambio de información de inteligencia entre los servicios de seguridad de los Estados miembros de la UE.

${ }_{21}$ Sobre los servicios de inteligencia, Lorena Bachmaier Winter, Información de inteligencia..., cit., pp. 48, 52, 53, 56, 57 y 89. El informe del Consejo Consultivo de Jueces del Consejo de Europa, reconoce que las investigaciones llevadas a cabo por los servicios de inteligencia son fundamentales para la detección y prevención de actos criminales, debiendo ser legales y estar sometidas a control democrático (p. 62).

Araucaria. Revista Iberoamericana de Filosofía, Política y Humanidades, año 18, $\mathrm{n}^{\circ} 36$. Segundo semestre de 2016. Pp. 439-463. ISSN 1575-6823 e-ISSN 2340-2199 doi: 10.12795/araucaria.2016.i36.19 
Continuando con el intercambio de información, el Tratado de Prüm de 27 de mayo de 2005, aunque no se trate un instrumento de la UE sino de un Tratado firmado por determinados Estados europeos, también ostenta gran utilidad tanto para la prevención como para la persecución. Éste se complementa con la Decisión 2005/671/JAI del Consejo, relativa al intercambio de información y a la cooperación en los delitos de terrorismo, vía Europol y Eurojust, constituyendo igualmente un instrumento de relevancia procesal. Entre las medidas preventivas contra el terrorismo que contiene el Tratado de Prüm (junto a otras para la lucha contra la delincuencia transfronteriza y la inmigración ilegal), destacamos la transmisión de información entre los Estados signatarios sin necesidad de previa petición para la prevención de atentados. Se trata de informar sobre personas específicas previamente investigadas, que permita deducir que pueden cometer actos terroristas, acceso a ficheros de $\mathrm{ADN}$, datos dactiloscópicos, otros datos de carácter personal y datos de vehículos, naves y aeronaves, incorporar escoltas armados en los vuelos, utilizar la asistencia policial recíproca, crear patrullas conjuntas y que los agentes puedan cruzar la frontera y adoptar medidas provisionales en otros Estados. A los datos e informaciones obtenidas en el marco de este Tratado, hay que añadir la información del Sistema de Información Schengen y Europol ${ }^{22}$. La Decisión 2008/615/JAI del Consejo ${ }^{23}$ extendió el Tratado de Prüm a todos los Estados miembros. Además se promulgaron la Decisión Marco 2008/315/ JAI, relativa a la organización y al contenido de intercambio de información de los registros antecedentes penales y la Decisión 2009/316/JAI del Consejo, que estableció el Sistema Europeo de Información de Antecedentes Penales (ECRIS $^{24}$, instrumentos normativos de la UE que completan los mecanismos de intercambio y transmisión de información.

Otras medidas de prevención que se destacan en la Estrategia, son el desarrollo de acciones comunes para identificar y abordar los comportamientos problemáticos, abordar la incitación y captación en determinados lugares como prisiones y lugares de culto, establecer un diálogo intercultural, explicar mejor las políticas europeas, promover el buen gobierno, la democracia, educación y la prosperidad económica, e investigar sobre la prevención y compartir experiencias y análisis. Vemos como la cooperación con terceros países,

${ }^{22}$ Véase José Carlos Remotti Carbonell, Las medidas contra el terrorismo en el marco del Tratado de Prüm, "Revista de Derecho constitucional europeo", 7 (2007), pp. 184, 186 y 203.

${ }^{23}$ La UE adoptó la Decisión 2008/615/JAI del Consejo de 23 de junio de 2008, sobre la profundización de la cooperación transfronteriza, en particular en materia de lucha contra el terrorismo y la delincuencia transfronteriza. Tiene como antecedente el Tratado de Prüm y las conclusiones del Consejo Europeo de Tampere de 1999, y como objetivo profundizar en la cooperación judicial y policial, con la creación y acceso a ficheros automatizados de ADN y suministro de información para la lucha contra el terrorismo, entre otros.

24 Joaquín J. Forner Delaygua y Natacha González Viada, op. cit., p. 167. El sistema ECRIS se creó en aplicación de la Decisión Marco 2009/315/JAI, relativa a la organización y contenido del intercambio de información de los registros de antecedentes penales entre los Estados miembros. 
tanto al desarrollo como en otros planos, al igual que trabajar dentro de la UE con otras etnias y culturas que puedan verse segregadas o marginadas, son fundamentales dentro de la prevención.

El segundo bloque de la Estrategia como hemos expuesto consiste en la protección. Tiene como finalidad la reducción de la vulnerabilidad de los posibles objetivos de los atentados y reducir su impacto. En concreto se trata de proteger las fronteras, transportes y todas las estructuras transfronterizas. Para la protección de las fronteras destaca la creación de la Agencia europea de fronteras (FRONTEX), el Sistema de Información Schengen (SIS II) y el Sistema de Información de Visados. Desde un punto de vista procesal hay que destacar la importancia adicional de estos dos sistemas para la persecución e investigación de los delitos de terrorismo.

El tercer pilar de la Estrategia consiste en la persecución e investigación de los terroristas más allá de las fronteras y conducirlos a disposición judicial, respetando los derechos humanos y el Derecho internacional. Estamos ante el aspecto en el que los instrumentos e instituciones de carácter procesal adquieren una importancia y protagonismo esencial. La UE requiere que se prive a los terroristas de los medios para cometer atentados y comunicarse, especialmente a través de internet, luchar contra la financiación del terrorismo, desarticular las redes y sus agentes de captación.

Para ello la UE ha reforzado las capacidades nacionales, recordemos nuevamente que son los Estados los auténticos protagonistas de la lucha contra el terrorismo. Cada Estado deberá informar sobre cómo ha reforzado su capacidad y mecanismos internos, conforme a las recomendaciones que se extraigan de la "evaluación entre iguales" de los acuerdos nacionales de lucha contra el terrorismo. Además se fomenta la cooperación judicial y policial con el pleno uso de Europol y Eurojust, y la integración de las evaluaciones de amenaza del SITCEN (Centro de Situación Común) para la elaboración de la política antiterrorista. Dentro de la persecución e investigación es fundamental el desarrollo del principio de reconocimiento mutuo, además del desarrollo del principio de disponibilidad e intercambio de información en materia policial y judicial, aspecto que ha sido tratado cuando expusimos la prevención y vimos los instrumentos normativos relevantes en la materia. Dado que gran parte de la amenaza terrorista se genera fuera de Europa, la persecución debe extenderse a nivel mundial. Para ello la UE debe fortalecer el consenso internacional con la ONU y otros organismos internacionales, perfeccionar acuerdos con interlocutores clave, incluyendo cláusulas antiterroristas e incluso un Convenio global con la ONU. Igualmente la UE deberá prestar asistencia a países prioritarios para instaurar mecanismos para la eliminación del terrorismo ${ }^{25}$.

${ }^{25}$ Parágrafos 22 a 31 de la Estrategia de la UE de lucha contra el terrorismo. 
En cuanto a la lucha contra la financiación del terrorismo, las medidas adoptadas en la UE se basan en las recomendaciones del Grupo de Acción Financiera Internacional. En este ámbito recientemente se ha promulgado la Directiva 2015/849/UE ${ }^{26}$, que tiene como objeto la prevención del blanqueo de capitales y la financiación del terrorismo, por lo que nuevamente encontramos este planteamiento desde la perspectiva de la estabilidad del sistema financiero, lo cual también se observa en la DOEI, como desarrollaremos más adelante. La Directiva 2015/849/UE tiene como fecha límite de transposición el 26 de junio de 2017, fecha que prácticamente coincide con la establecida para la DOEI. De este modo en estas fechas en principio tendremos en la UE un nuevo marco normativo transpuesto respecto a estas dos cuestiones específicas, la obtención de pruebas y la financiación del terrorismo. En cuanto a la lucha contra la financiación del terrorismo, también hay que destacar la reciente Directiva 2014/42/UE del Parlamento Europeo y del Consejo, sobre el embargo y el decomiso de los instrumentos y del producto del delito en la $\mathrm{UE}^{27}$, que se aplica a las infracciones contempladas en la Decisión Marco 2002/475/JAI del Consejo, sobre la lucha contra el terrorismo.

Como ya hemos dicho, a partir de 2001 se incrementaron de forma significativa las disposiciones y medidas de la UE para combatir el terrorismo. Gran parte de las mismas están dirigidas a la persecución e investigación. Además de las disposiciones anteriormente expuestas cuando tratamos la transferencia de información e inteligencia en la prevención, las cuales igualmente son predicables en el ámbito de la persecución, existen otras instituciones que fueron creadas en aquel momento y que además de servir en éste ámbito, desarrollan el espacio de libertad, seguridad y justicia. En este ámbito destacamos la creación de Eurojust en 2002 y la utilidad Red Judicial Europea en materia penal (RJE), que aunque fue creada en $1998^{28}$ constituye una herramienta para facilitar la cooperación judicial en la lucha contra la delincuencia transnacional. La RJE está constituida por puntos de contacto de

${ }^{26}$ Directiva (UE) 2015/849 del Parlamento Europeo y del Consejo, de 20 de mayo de 2015, relativa a la prevención de la utilización del sistema financiero para el blanqueo de capitales o la financiación del terrorismo, por la que se modifica el Reglamento (UE) n ${ }^{\circ}$ 648/2012 del Parlamento Europeo y del Consejo relativo a los derivados extrabursátiles, las entidades de contrapartida central y los registros de operaciones, y se derogan la Directiva 2005/60/CE del Parlamento Europeo y del Consejo, relativa a la prevención de la utilización del sistema financiero para el blanqueo de capitales y financiación del terrorismo y la Directiva 2006/70/CE de la Comisión, por la que se establecen disposiciones de aplicación e la Directiva 2005/60/CE en lo relativo a la definición de "personas del medio político"y los criterios técnicos aplicables en los procedimientos simplificados de diligencia debida con respecto al cliente, así como en lo que atañe a la exención por razones de actividad financiera ocasional o muy limitada.

27 Recientemente incorporada al ordenamiento español por la Ley 41/2015, de 5 de octubre, de modificación de la LECRIM para la agilización de la justicia penal y el fortalecimiento de las garantías procesales.

28 Surge con la Acción Común adoptada por el Consejo el 29 de junio de 1998, sustituida por la Decisión del Consejo de 16 de diciembre de 2008. 
las autoridades judiciales de los Estados de la UE, que proporcionan información jurídica y práctica para la eficacia de las solicitudes de cooperación. Para ello la RJE ha creado el "European Judicial Network (EJN)" (Atlas Judicial Penal $)^{29}$, que facilita el trabajo en la presentación y ejecución de las solitudes de cooperación y asistencia judicial penal. EL EJN permite determinar cuál es la autoridad competente para recibir una solicitud de cooperación o asistencia judicial penal y permite transmitir directamente las solicitudes de forma ágil y eficiente. En cada diligencia, sistematizadas a través de las 42 fichas belgas que comparan la regulación de cada una de ellas en el Estado emisor y en el receptor de la solicitud, es frecuente que se diferencie entre el tratamiento procesal del terrorismo y el resto de las materias.

En el contexto de la reacción tras 2001 en la UE, se adoptó la Decisión Marco 2002/475/JAI ${ }^{30}$, que constituyó la primera medida de envergadura para poner en práctica la Resolución del Consejo de Seguridad de Naciones Unidas 1373 (2001), lo cual se hizo rápidamente. Esta Decisión Marco tuvo como objetivo fundamental armonizar la legislación penal, en cuanto a la tipificación de las conductas terroristas y el establecimiento de sanciones, creando una definición común de terrorismo que carecía de precedentes a nivel internacional, además de incorporar disposiciones sobre la protección de las víctimas. La mencionada Resolución 1373 (2001) fue esencial para superar los recelos soberanistas de algunos Estados de la UE, armonizar y reforzar los ordenamientos internos y favorecer la cooperación judicial y policial ${ }^{31}$. Por ello esta Decisión Marco y la Decisión Marco 2002/584/JAI por la que se crea la orden europea de detención y entrega, constituyeron los primeros pilares de la política antiterrorista. Trataremos este instrumento de reconocimiento mutuo junto con otros relevantes para la persecución, en concreto el embargo preventivo y aseguramiento de pruebas, el exhorto europeo de obtención de pruebas y la nueva orden europea de investigación (OEI), en el siguiente apartado, en el que veremos la entrega de personas y la obtención de pruebas, fundamentales para la persecución e investigación. La relevancia de estos instrumentos fundamentados en el principio de reconocimiento mutuo, requieren una atención más detallada.

Continuando con la Estrategia, otro de los instrumentos que se establece para la persecución consiste en la creación de los equipos conjuntos de investigación, regulados por la Decisión Marco del Consejo 2002/465/JAI, sobre equipos conjuntos de investigación ${ }^{32}$. La DOEI expresamente excluye de su ámbito de

\footnotetext{
${ }^{29} \mathrm{http}: / / w w w . e j n-c r i m j u s t . e u r o p a . e u /$ ejn/EJN_Home.aspx

${ }^{30}$ Fue modificada por la Decisión Marco 2008/919/JAI del Consejo, incorporada al ordenamiento español con la reforma del CP llevada a cabo por la LO 5/2010, el cual ha sido recientemente reformado en esta materia por la LO 2/2015.

${ }^{31}$ Sobre la Decisión Marco 2002/475/JAI, Joaquín J. Forner Delaygua y Natacha González Viada, op. cit., pp. 162 a 164.

32 Transpuesta al ordenamiento español por la Ley 11/2003, de 21 de mayo, reguladora de los 
aplicación tanto la creación de los equipos como la obtención de pruebas por los mismos, constituyendo una excepción a la aplicación de la OEI a todas las medidas de investigación que se acuerden para la obtención de pruebas ${ }^{33}$, por lo que tratamos esta institución por separado. Como se puede comprobar por la fecha, este instrumento se contextualiza tras los atentados de 2001, momento en el que la lucha contra el terrorismo se convierte en una prioridad y se incrementan de forma importante las disposiciones y medidas al respecto, como hemos visto. Por ello como se refleja en el Considerando $n^{0} 7$ de la Decisión Marco, el Consejo Europeo considera que los equipos deben crearse prioritariamente para la lucha contra los delitos cometidos por los terroristas ${ }^{34}$.

Los equipos conjuntos de investigación se constituyen previo acuerdo de las autoridades competentes de dos o más Estados de laUE, cuando su creación se solicite por uno de ellos para efectuar investigaciones penales en un territorio concreto o de todos los Estados que participen en el equipo, para actuar de forma coordinada con un fin específico y un período limitado. En la norma de transposición española se establece además que nuestra autoridad competente dará preferencia en todo caso, a la creación de los equipos cuando las investigaciones estén relacionadas con delitos de terrorismo. Cuando sea necesario practicar diligencias de investigación en el territorio de un Estado en el que se ha constituido el equipo, se podrá solicitar a las autoridades que se autoricen dichas diligencias en las mismas condiciones que si hubieran sido solicitadas en el ámbito de una investigación nacional, obviándose los cauces ordinarios de la asistencia judicial. No obstante a pesar de lo prometedor que parecía en su momento la creación de estos equipos, los Estados los han utilizado de forma muy limitada y fundamentalmente se han constituido a través de acuerdos bilaterales. Además la Decisión Marco no sigue el principio forum regit actum, a diferencia del Convenio de Asistencia Judicial de 2000, y la Decisión Marco no determina el alcance probatorio que pudieran tener las diligencias de investigación realizadas, lo cual no provoca problemas ante los Órganos Jurisdiccionales del Estado donde se practicó la diligencia de investigación, si bien para su eficacia en otro Estado habrá que tener en cuenta la lex loci y comprobar si no se han vulnerado los principios esenciales del Estado donde tengan que tener efectos procesales ${ }^{35}$.

equipos conjuntos de investigación penal en el ámbito de la UE, y por la LO 3/2003 de la misma fecha y complementaria de la anterior, por la que se establece el régimen de responsabilidad penal de los miembros destinados en dichos equipos cuando actúen en España.

${ }_{33}$ Así se establece en el Considerando 8 y en el artículo 3 DOEI.

34 De hecho el Consejo Europeo de Tampere de 1999, instó a la creación inmediata de los equipos conjuntos de investigación, como primer paso para la lucha contra el narcotráfico, trata de seres humanos y contra el terrorismo. Ello se refleja igualmente en la Exposición de Motivos de la Ley $11 / 2003$, que comienza observando que las premisas establecidas en el Consejo Europeo de Tampere, han adquirido una mayor relevancia tras los atentados del 11 de septiembre de 2001, y que uno de los instrumentos para la lucha contra el terrorismo es precisamente la creación de los equipos conjuntos de investigación.

${ }^{35}$ Respecto a la utilización práctica y eficacia de las pruebas obtenidas, Julio Pérez Gil, Equipos conjuntos de investigación penal, [en Mar Jimeno Bulnes coord.: La cooperación judicial civil y penal 
El cuarto y último bloque de la Estrategia, consiste en la respuesta a los atentados. Para ello es fundamental gestionar y minimizar dichas consecuencias, coordinar la respuesta, la protección civil, la puesta en marcha del Dispositivo Integrado de Respuesta Política a las Crisis (adoptado por el Consejo en junio de 2013), la asistencia a las víctimas y la puesta en común de buenas prácticas en la asistencia a las víctimas del terrorismo.

Entre las prioridades de la respuesta destacamos la aplicación de la cláusula de solidaridad del artículo 222 TFUE, conforme a la Decisión del Consejo de 24 de junio de 2014. La aplicación de esta cláusula carece de repercusiones en el ámbito de defensa. Una vez invocada por un Estado que haya padecido un ataque terrorista, el Consejo asume la dirección política y estratégica, respetando las iniciativas de la Comisión y del Alto Representante de la Unión para Asuntos Exteriores y Política de Seguridad, y en el supuesto de ataque terrorista la Presidencia estará asesorada por el Coordinador de la lucha contra el terrorismo. Dicha Decisión se aplica sin perjuicio de la invocación del artículo 42.7 TUE, que regula la defensa colectiva cuando un Estado sea objeto de una agresión armada en su territorio ${ }^{36}$.

En cuanto a la atención a las víctimas destacamos la Directiva 2012/29/UE, que otorga un tratamiento específico a las víctimas de terrorismo, especialmente para determinar sus necesidades especiales de protección. Esta Directiva ha sido recientemente incorporada al ordenamiento español por la Ley 4/2015, un auténtico código de derechos procesales y extraprocesales de las víctimas de delito, que reconoce derechos inéditos a las asociaciones de víctimas en cuanto a la participación en el proceso como parte acusadora superando con creces los mínimos exigidos en la Directiva, lo cual posee una especial virtualidad para las asociaciones de víctimas del terrorismo. Igualmente extiende el derecho de información y participación en el proceso, de tal forma que las víctimas pueden incluso recurrir las resoluciones que se dicten durante la ejecución de la condena, entre otras importantes innovaciones. El reconocimiento de los derechos de la víctima en el proceso penal constituye una conquista irrenunciable, habiendo sido la eterna preterida en este proceso. Sus derechos tienen que ser conciliados con los del investigado, acusado o condenado, lo cual posee una especial importancia en materia de terrorismo, donde como hemos visto, se pueden excepcionar ciertos derechos fundamentales de carácter procesal ${ }^{37}$.

en el ámbito de la Unión Europea: instrumentos procesales, Bosch editor, Universidad de Burgos, 2007], pp. 352, 353, 365 у 366.

${ }^{36}$ Invocada por primera vez por Francia tras los atentados del 13 de noviembre de 2015.

${ }^{37}$ En cuanto a la Directiva y el Estatuto de la Víctima, Ángel Tinoco Pastrana, La participación de las asociaciones de víctimas como parte acusadora en el proceso penal y el nuevo Estatuto de la víctima del delito, por el que se transpone la Directiva 2012/29/UE, "Cuadernos de Política Criminal", 115 (2015), pp. 275, 288, 299 y 301. Es interesante que el Estatuto se hace público como Anteproyecto, tres días después de la sentencia del TEDJ en el asunto Del Río Prada v. España (21 de octubre de 2013), por la que se deroga la denominada "doctrina Parot", lo cual tuvo una gran 


\section{Instrumentos de reconocimiento mutuo para la entrega de personas y obtención de pruebas}

\section{La orden europea de detención y entrega (OEDE), creada por la Decisión} Marco 2002/584/JAI ${ }^{38}$, fue el primer instrumento de reconocimiento mutuo, siendo desde su creación el "instrumento estrella" en la cooperación judicial penal europea ${ }^{39}$. Fue además la primera vez que se creó un "título judicial unificado", en parte clave de su éxito, y supuso la eliminación del control del ejecutivo respecto a los tradicionales procedimientos extradicionales. Constituye un exitoso instrumento de reconocimiento mutuo ${ }^{40}$ que como se destaca en la Estrategia, ha demostrado constituir una importante herramienta para la persecución e investigación de terroristas fuera de las fronteras. La autoridad judicial de un Estado miembro podrá emitir una OEDE para el ejercicio de acciones penales si los hechos están conminados con penas o medidas de seguridad privativas de libertad, o medidas de internamiento en régimen cerrado de un menor, con una penalidad abstracta de al menos doce meses de duración, o bien para el cumplimiento de penas, medidas de seguridad o internamiento similares, de al menos cuatro meses de duración. La OEDE constituye una resolución judicial para la detención y entrega por otro Estado miembro de una persona reclamada para el ejercicio de acciones penales, ejecución de una pena, medida de seguridad o medida de internamiento en un centro de

repercusión entre las asociaciones de víctimas de terrorismo, por lo que parece que intenta satisfacer determinadas demandas de las mismas (p. 274).

${ }^{38}$ Fue incorporada al ordenamiento español por la Ley $3 / 2003$ y la LO 2/2003, complementaria de la anterior, ambas de 14 de marzo, actualmente derogadas por la Ley 23/2014, de 20 de noviembre, de reconocimiento mutuo de resoluciones penales en la UE y la LO 6/2014, de 29 de octubre, complementaria de ésta. La Ley 23/2014 inaugura una nueva técnica legislativa y supera la incorporación individual de cada Decisión Marco o Directiva reguladoras de instrumentos de reconocimiento mutuo. Crea un esquema en el que se facilita la incorporación de las Directivas que se adopten o aún no estén transpuestas, por lo que reduce la dispersión normativa y la complejidad del ordenamiento, constituyendo una auténtica codificación de la incorporación al ordenamiento español de los instrumentos de reconocimiento mutuo.

39 Así lo destaca Mar Jimeno Bulnes, La orden europea de detención y entrega: análisis normativo, [en Coral Arangüena Fanego, Montserrat de Hoyos Sancho y Carmen Rodríguez-Medel Nieto, coords.: Reconocimiento Mutuo de Resoluciones Penales en la Unión Europea, Cizur Menor, Thomson Reuters Aranzadi, CGPJ, Instituto de Estudios Europeos de la Universidad de Valladolid, 2015], pp. 38 y 39. Observa que la Comisión presentó la propuesta de la creación de la orden europea de detención y entrega, sólo ocho días tras los atentados del 11 de septiembre de 2001, suceso que generó un cambio en la política y legislación de numerosos Estados para luchar contra el terrorismo internacional, para lo cual la orden se revela como la medida procesal más idónea. Las negociaciones para conseguir el acuerdo de todos los Estados en el Consejo, que entonces requería unanimidad, concluyeron en sólo tres meses. La primera legislación que adaptó el ordenamiento interno a la Decisión Marco fue la española, la última la italiana, y Alemania tuvo que promulgar dos normas como consecuencia de la sentencia que dictó el Tribunal Constitucional alemán.

${ }^{40} \mathrm{Su}$ transcendencia refleja en el relevante acervo jurisprudencial que se ha creado sobre este instrumento. Entre otras destacamos al respecto, las Sentencias del TJUE de 26 de febrero de 2013 (Gran Sala), 30 de mayo de 2013 (Sala Segunda), 28 de junio de 2012 (Sala Tercera), las Sentencias del TC 26/2014, 113/2014, 50/2014, 181/2011 y las Sentencias del TS 915/2012, 735/2012 y 188/2010. 
menores. Esta resolución se documentará en un formulario común a todos los Estados miembros (título judicial unificado), que se transmitirá directamente a la autoridad judicial de ejecución, y si no se conociera su paradero o de forma simultánea a la transmisión directa referida, la persona requerida será descrita por la autoridad de emisión en el Sistema de Información de Schengen ${ }^{41}$ SIS II al que antes hicimos referencia. Si no fuera posible acudir a este Sistema, la autoridad judicial de emisión podrá recurrir a los servicios de Interpol para la comunicación de la $\mathrm{OEDE}^{42}$.

La resolución judicial por la que se decide la entrega de la persona reclamada, se adoptará por la autoridad judicial de ejecución en distintos plazos en función de que aquélla consienta (10 días) o no consienta la entrega (60 días), excluyéndose el control de la doble tipificación si el delito está incluido en la lista de 32 delitos (común a todos los instrumentos de reconocimiento mutuo), y éstos están conminados con al menos tres años de privación de libertad como penalidad abstracta, lista en la que se incluyen los delitos de terrorismo ${ }^{43}$. Entre las causas de denegación por el Estado de ejecución hay que diferenciar entre las obligatorias y las facultativas, y en ellas aparte de las derivadas de los límites externos de la jurisdicción de cada Estado y por tanto de su propia soberanía, destacan las que garantizan los derechos fundamentales de carácter procesal, además de otros de naturaleza penal basados en el principio de intervención mínima. Caben además las posibilidades del traslado temporal de la persona requerida, de la entrega condicionada y la entrega suspendida, y por otro lado, la entrega de los objetos que constituyan piezas de convicción o pruebas del delito ${ }^{44}$.

La OEDE constituye el instrumento de reconocimiento mutuo de mayor éxito y estadísticamente más utilizado, en gran medida como consecuencia del funcionamiento de instrumentos orgánicos de cooperación judicial, como la RJE y otros de índole telemática establecidos a nivel europeo y nacional. Además por la importante labor desempeñada por el TJUE en la interpretación de este instrumento, y por las relevantes aportaciones de otras normas europeas y nacionales de reconocimiento mutuo para la cooperación judicial europea en materia penal, tales como la aproximación legislativa establecida en el artículo

${ }^{41}$ Mar Jimeno Bulnes, op.cit., p. 49. La alerta en el sistema SIS resulta equiparable al formulario de la OEDE, aunque desde el Consejo General del Poder Judicial (CGPJ) se aconseja que se proceda al posterior envío del mismo traducido al idioma exigido, en el plazo establecido para ello en el Estado de ejecución, cuando se localice el paradero de la persona sobre la recae la orden.

${ }^{42}$ Respecto al objeto, contenido, documentación y transmisión de la OEDE, artículos 34, 36, 37 y 40 Ley 23/2014.

${ }^{43}$ Vemos aquí la importancia de la DM 2002/475/JAI, coetánea de la Decisión Marco reguladora de la OEDE, dado que supuso la armonización del Derecho material en cuanto a la definición de los delitos de terrorismo y por tanto, que el principio de reconocimiento mutuo y la armonización de los ordenamientos, constituyen extremos que están estrechamente unidos.

${ }^{44}$ En cuanto a la entrega de la persona requerida, véanse los artículos 47 a 49, 52 y 54 a 59 Ley 23/2014, entre otros. 
82.1 TFUE, complemento indispensable del principio de reconocimiento mutuo $^{45}$.

Otro instrumento de reconocimiento mutuo posterior aunque prácticamente coetáneo, es el creado por la Decisión Marco 2003/577/JAI del Consejo, relativa a la ejecución en la UE de las resoluciones de embargo preventivo de bienes y aseguramiento de pruebas ${ }^{46}$. Aunque este instrumento no se destaca expresamente en la Estrategia, tenemos que exponerlo dado el contexto en el que se creó, porque constituye un instrumento de reconocimiento mutuo y su estrecha relación con el exhorto europeo de obtención de pruebas, el cual sí se destaca en la Estrategia y que también va a ser expuesto. Este instrumento tiene como finalidad servir de forma general, para agilizar la gestión de los bienes embargados o asegurados en los procesos penales, tras detectarse importantes deficiencias en el sistema de la cooperación judicial penal derivadas de la soberanía de los Estados, las barreras lingüísticas y la lentitud de los instrumentos tradicionales. Desde la UE se fomentó con esta Decisión Marco una versión equivalente a la circulación de mercancías, que las pruebas puedan circular sin barreras para su incorporación y plena eficacia en el proceso penal de cualquier Estado de la Unión ${ }^{47}$.

Ello suscitó importantes críticas, dado que las pruebas no constituyen productos, tienen que ser contempladas desde un punto de vista funcional (averiguación de la verdad y justicia) y además están en juego los derechos fundamentales, a diferencia del fin de la circulación de mercancías que consiste en la liberalización como fin absoluto. El problema fundamental reside por tanto en la necesidad de armonizar los códigos procesales penales en materia probatoria, y hasta que se produzca el criterio preferible parece ser el principio forum regit actum, que permite una extensa evaluación de la práctica probatoria de otro Estado, conforme a las medidas funcionales del juez interno ${ }^{48}$.

Pero ha tenido un más que cuestionable éxito al limitarse a la aprehensión de los efectos y no regular las medidas de investigación para localizarlos ni su posterior traslado al Estado de emisión, para lo cual es necesario utilizar otros instrumentos conforme a las normas de asistencia mutua en materia penal. No crea un título judicial unificado, a diferencia de la Decisión Marco anterior reguladora de la OEDE, por lo que junto con la resolución que se adopte por la autoridad de emisión hay que remitir un certificado. Además

\footnotetext{
${ }^{45}$ Sobre el éxito del instrumento, Mar Jimeno Bulnes, op. cit., pp. 74 a 76.

46 Incorporada al ordenamiento español con la Ley 18/2006 de 5 de junio y la LO 5/2006 de 1 de julio, complementaria de la anterior, actualmente derogadas por la Ley 23/2014 y la LO 6/2014, anteriormente referidas.

47 Véase Ángel Tinoco Pastrana, El embargo preventivo y el aseguramiento de pruebas en los procesos penales en la UE. Novedades tras la Ley 23/2014, de reconocimiento mutuo de resoluciones penales en la Unión Europea y la Directiva 2014/41/CE relativa a la orden europea de investigación en materia penal, "Cuadernos Europeos de Deusto", 52 (2015), p. 124.

${ }^{48}$ Respecto a dichas críticas, Klaus Tiedemann, op. cit., pp. 440 y 441.
} 
coexiste con los instrumentos tradicionales de asistencia judicial y policial, por lo que encontramos en esta materia un marco fragmentario y complicado que ha provocado que en la práctica se utilice muy poco, lo cual posee su reflejo en los Informes de la Comisión. Y ello a pesar de la gran relevancia de la materia para la cooperación judicial penal internacional, dado que versa sobre los elementos objetivos de la instrucción y enjuiciamiento, es decir, sobre las piezas de convicción y las pruebas, fundamentales para la fundamentación de la sentencia. Como consecuencia de ello el principio de reconocimiento mutuo, sustitutorio de la tradicional asistencia mutua, ha tenido una reducida virtualidad práctica en este ámbito. Las autoridades judiciales han optado por no usar este instrumento, ya que parece que no le encuentran un valor añadido respecto a los tradicionales convenios internacionales de asistencia judicial en materia penal, solapándose instrumentos normativos con principios diferentes aunque teóricamente compatibles. Es difícil que pueda entender una autoridad judicial que tenga que emitir una comisión rogatoria con fines probatorios y simultáneamente un certificado con su resolución en cuanto al aseguramiento de bienes ${ }^{49}$.

Estos importantes déficits pueden solventarse con la DOEI, promulgada en cumplimiento del Programa de Estocolmo. La DOEI sustituye la disposiciones de la Decisión Marco en relación al aseguramiento de pruebas y posee un espectro de aplicación mucho más extenso, comprendiendo las diligencias de investigación, obtención de pruebas y su ulterior traslado, con una finalidad tanto respecto a la investigación como de carácter cautelar, solventando por tanto los inconvenientes anteriormente descritos en cuanto al aseguramiento de pruebas por la Decisión Marco. Además crea un título judicial unificado, por lo que en este sentido se equipara con la OEDE, es decir introduce una herramienta procesal similar en cuanto a los elementos objetivos del proceso penal, como se hizo en 2002 respecto al elemento subjetivo, las personas requeridas. Por ello, si bien los inconvenientes expuestos subsisten en cuanto al embargo preventivo, pueden ser solventados en cuanto a las pruebas con la OEI cuando se transponga la Directiva ${ }^{50}$, para lo cual la fecha límite es el 22 de mayo de $2017^{51}$.

\footnotetext{
${ }^{49}$ Así lo destaca Francisco Jiménez-Villarejo, Ejecución en la Unión Europea de las resoluciones que impongan sanciones pecuniarias. Comentarios a la Ley 1/2008, de 4 de diciembre, [en Coral Arangúena Fanego, coord.: Espacio Europeo de Libertad, Seguridad y Justicia, Valladolid, Lex Nova, 2010], p. 312.

${ }^{50}$ Sobre los inconvenientes de este instrumento y la Orden Europea de Investigación, Ángel Tinoco Pastrana, El embargo preventivo..., cit., pp. 125 a 127, 129 y 133.

51 Si bien la DOEI formalmente no ha sido transpuesta a nuestro ordenamiento, podemos afirmar que en parte esta transposición se ha realizado. Por un lado con la promulgación de la Ley 23/2014 de reconocimiento mutuo, cuyo Título Preliminar regula el "Régimen general de reconocimiento mutuo de resoluciones penales en la UE", el cual es plenamente aplicable a la OEI. Por otro, por la reciente reforma de la LECRIM, por la LO 13/2015, de 5 de octubre, de modificación de la LECRIM para el fortalecimiento de las garantías procesales y las medidas de investigación tecnológicas, que soluciona
} 
En la Estrategia de lucha contra el terrorismo se destaca la utilidad para responder a los objetivos de la persecución junto con la OEDE, del exhorto europeo de obtención de pruebas (EEP) para recabar objetos, documentos y datos destinados a procedimientos en materia penal, instrumento de reconocimiento mutuo creado por la Decisión Marco 2008/978/JAI, de 18 de diciembre. En realidad consideramos que lo que identifica la Estrategia es la cuestión de la importancia de las piezas de convicción y de las pruebas para la persecución del terrorismo, dado que como vamos a ver, este instrumento de reconocimiento mutuo como tal posee una muy dudosa eficacia y utilidad en estos extremos y gran parte de las objeciones expuestas en el anterior instrumento, al igual que las críticas en cuanto al tratamiento de las pruebas, la protección de los derechos fundamentales y la falta de armonización de los códigos procesal penales de los Estados de la UE. Por otro lado, vemos como a pesar de destacarse expresamente este instrumento en la Estrategia, la Decisión Marco ha sido incorporada al ordenamiento español con mucho retraso, ya que no se ha hecho hasta la Ley $23 / 2014$, a pesar de que la fecha límite para ello expiró el 19 de enero de $2011^{52}$.

El EEP constituye una resolución emitida por la autoridad judicial de un Estado miembro para recabar objetos, documentos y datos de otro Estado miembro para su utilización en un proceso penal. Pero se aplica a la prueba ya existente por lo que sólo cubre un limitado espectro de la cooperación judicial penal en lo referente a las pruebas. Por ello es facultativa su utilización y las autoridades competentes pueden acudir a otros procedimientos de asistencia judicial $^{53}$. El EEP pretende paliar las deficiencias expuestas del embargo preventivo y aseguramiento de pruebas y complementar la cooperación judicial en materia probatoria. Pero el EEP al llevar implícito el aseguramiento de las pruebas, en la práctica dejaría sin virtualidad práctica gran parte de las disposiciones de la Decisión Marco 2003/577/JAI solapándose ambos instrumentos, problema que como vimos además ya tenía esta Decisión Marco con los tradicionales convenios de asistencia mutua, a lo cual se une la coexistencia del EEP con dichas normas convencionales de asistencia y

el importante problema que tenía la legislación española, en cuanto a la insuficiencia o carencia de regulación de las mencionadas diligencias de investigación, por lo que parece estar enfocada a la aplicación futura de la DOEI.

${ }^{52}$ Lorena Bachmaier Winter, El exhorto europeo de obtención de pruebas: análisis normativo, [en Coral Arangüena Fanego, Montserrat de Hoyos Sancho y Carmen Rodríguez-Medel Nieto, coords.: Reconocimiento Mutuo de Resoluciones Penales en la Unión Europea, Cizur Menor, Thomson Reuters Aranzadi, CGPJ, Instituto de Estudios Europeos de la Universidad de Valladolid, 2015], pp. 507 y 508. Casi se puede afirmar que esta transposición tardía pudo estar forzada por el artículo 10 del Protocolo 36 del Tratado de Lisboa, que introduce un plazo transitorio de cinco años respecto a las atribuciones de la Comisión en cooperación judicial y policial en materia penal en el artículo 258, plazo que expiró el 1 de diciembre de 2014. Si España no hubiera transpuesto esta Decisión Marco, la Comisión podría reclamar su cumplimiento a través del recurso de infracción ante el TJUE.

${ }^{53}$ En cuanto a estas objeciones, Considerando 4 DOEI. 
que no es obligatorio utilizarlo, como acabamos de exponer. Vemos por tanto nuevamente en materia probatoria un marco fragmentario de instrumentos de cooperación penal, que genera dificultades adicionales al no simplificarla. Además el EEP posee un reducido ámbito de aplicación y no permite practicar medidas de investigación restrictivas de derechos fundamentales, para lo cual hay que acudir a otros mecanismos de cooperación judicial. A todo ello se une su reciente y más que tardía incorporación al Derecho español y que este instrumento se sustituye por la anteriormente referida DOEI, por lo cual el EEP tiene una vigencia muy limitada y es dudoso que vaya a adquirir un mínimo de virtualidad práctica ${ }^{54}$.

La DOEI deroga el EEP ${ }^{55}$, las disposiciones de la Decisión Marco 2003/577/ JAI en cuanto al aseguramiento de las pruebas y las disposiciones correspondientes de otros instrumentos convencionales que se aplican a las relaciones entre los Estados vinculados por la DOEI. Se trata del Convenio Europeo de Asistencia Judicial en Materia Penal, del Convenio relativo a la aplicación del acuerdo de Schengen y del Convenio relativo a la asistencia judicial en materia penal entre los Estados de la UE y su Protocolo, complementarios de los instrumentos de reconocimiento mutuo existentes. Además la OEI posee un espectro de aplicación muy amplio, abarcando las diligencias de investigación, la obtención de pruebas y su traslado y sirve tanto para acordar diligencias de investigación como medidas cautelares. Además introduce un título judicial unificado en la materia del mismo modo que la OEDE, lo cual vimos constituye un factor importante para su éxito. La OEI constituye por tanto un ambicioso instrumento que codifica la fragmentaria e incluso confusa regulación actualmente existente, y además intenta solventar la mayor parte de los inconvenientes que presentan los dos anteriores instrumentos de reconocimiento mutuo que acabamos de exponer. Pero también tenemos que tener en cuenta el diverso contexto en el que se crea la OEI, dado que la crisis financiera parece haber desplazado en gran medida a la preocupación prioritaria que existía en 2002 en cuanto a la amenaza terrorista. Contextualizar los instrumentos de reconocimiento mutuo no es baladí, como comprobamos en la OEI en el tratamiento que se confiere a la información sobre cuentas y operaciones bancarias o financieras y a la inmovilización de $\operatorname{activos}^{56}$. A pesar de ello no es aventurado afirmar que cuando la OEI entre en funcionamiento habrá un antes y un después en la materia, al fomentarse la libre circulación de pruebas en la UE, que este nuevo instrumento constituye un avance comparable al que supuso en su momento la OEDE y que posee una importante virtualidad en la lucha contra el terrorismo.

\footnotetext{
${ }^{54}$ Respecto a los defectos del EEP, Lorena Bachmaier Winter, El exhorto europeo..., op. cit, pp. $509,510,529$ y 530 .

${ }^{55}$ La DM 2008/978/JAI ha sido derogada posteriormente por el Reglamento (UE) 2016/95, si bien el EEP ejecutado con arreglo a la DM 2008/978/JAI continuará rigiéndose por ésta, hasta que el proceso concluya con resolución firme.

${ }^{56}$ Véase Ángel Tinoco Pastrana, El embargo preventivo..., cit., p. 127.
} 
El principio de reconocimiento mutuo conlleva la ejecución de la resolución extranjera de forma prácticamente automática, sin que sea necesario comprobar su conformidad con el ordenamiento interno, estando tasadas las causas de denegación. Pero como expusimos ut supra, son frecuentes las reticencias respecto a la libre circulación de pruebas, en cuanto a la protección de los derechos fundamentales. Por ello la DOEI junto al principio de proporcionalidad introduce el principio de necesidad conforme a los fines del proceso y los derechos fundamentales, lo cual puede ser controlado por el Estado de ejecución. Esta novedad de la Directiva que ubica el respeto de los derechos fundamentales en un plano prioritario, en consonancia con el Tratado de Lisboa ${ }^{57}$, puede suponer una reducción del alcance del principio de reconocimiento mutuo, realizando la DOEI importantes referencias en cuanto al reconocimiento y ejecución de la OEI a la conformidad con el Derecho interno del Estado de ejecución. Una importante novedad de la Directiva consiste en la exclusión del control de la doble tipificación si la OEI versa sobre las medidas de investigación que de forma preceptiva tendrán que existir en todas las legislaciones nacionales, conforme al artículo 10.2. Es decir, se introduce un nuevo supuesto de naturaleza eminentemente procesal en el que no será necesario dicho control de la doble tipificación. Por tanto aunque la OEI no se emita respecto a alguno de los 32 delitos de la lista común a todos los instrumentos de reconocimiento mutuo, con los requisitos de penalidad expuestos cuando tratamos la OEDE en los que está excluido este control, si versara sobre una diligencia de investigación del referido precepto, tampoco se llevará a cabo el control de la doble tipificación, con la condición de que la legislación procesal penal esté armonizada. Es indudable el importante efecto armonizador de la Directiva en la legislación procesal respecto a las diligencias sumariales de investigación ${ }^{58}$, de gran importancia para la protección de los derechos fundamentales.

Por tanto un aspecto importante de la Directiva estriba en la profunda preocupación por el respeto de los derechos fundamentales, matizando el entendimiento anterior del principio de reconocimiento mutuo por la desconfianza de los Estados y sus reticencias a reconocer y/o ejecutar a ciegas las medidas solicitadas ${ }^{59}$. Ello se pone de manifiesto en la Directiva en las nuevas

\footnotetext{
${ }^{57}$ María Pía Calderón Cuadrado, op. cit., pp. 112 a 117. El Tratado de Lisboa consolida el espacio de libertad, seguridad y justicia en torno al ciudadano como persona y por tanto, dentro del respeto de los derechos fundamentales. En la cooperación penal la protección uniforme y real a través de garantías, es lo que realmente posibilitará la vigencia del reconocimiento mutuo. Este principio se conserva como piedra angular pero ha sido reformulado.

${ }^{58}$ De hecho, observamos que en gran medida la reciente LO 13/2015, de 5 de octubre, de modificación de la LECRIM para el fortalecimiento de las garantías procesales y las medidas de investigación tecnológicas, supone la regulación de tales diligencias en nuestro ordenamiento, y por tanto en este extremo la incorporación de la Directiva.

${ }^{59}$ Mariem Aguilera Morales, El exhorto europeo de investigación: a la búsqueda de la eficacia y la protección de los derechos fundamentales en las investigaciones penales transfronterizas, Boletín del Ministerio de Justicia, 2145 (2012), p. 4.
} 
causas de no reconocimiento y no ejecución y en las importantes concesiones a la lex loci es decir, al principio locum regit actum. Este principio permite que la autoridad de ejecución recurra a otra medida de investigación diferente a la indicada en la OEI, controlándose por dicha autoridad el contenido de la OEI, al priorizarse los principios de proporcionalidad y necesidad de conformidad con el ordenamiento del Estado de ejecución. En conclusión, si bien se solventarán gran parte de los inconvenientes de la actual regulación, se reduce la aplicación del principio que fue definido en el Consejo de Tampere como "la piedra angular de la cooperación judicial y policial", conforme se venía haciendo en los primeros instrumentos. No obstante, observamos que estas innovaciones no tienen por qué constituir un obstáculo para la cooperación judicial y policial, sino que por el contrario la fomenta, aprovechando la experiencia de estos primeros instrumentos creados en un contexto diferente. Además la profunda preocupación de la DOEI por el respeto de los derechos fundamentales requiere una valoración positiva ${ }^{60}$.

${ }^{60}$ Véase Ángel Tinoco Pastrana, El embargo preventivo..., cit., pp. 135 y 139. 


\section{Referencias bibliográficas:}

Bachmaier Winter, Lorena, Información de inteligencia y proceso penal, [en Lorena Bachmaier Winter, coord.: Terrorismo, proceso penal y derechos fundamentales, Madrid, Marcial Pons, 2012].

El exhorto europeo de obtención de pruebas: análisis normativo, [en Coral Arangüena Fanego, Montserrat de Hoyos Sancho y Carmen Rodríguez-Medel Nieto, coords.: Reconocimiento Mutuo de Resoluciones Penales en la Unión Europea, Cizur Menor, Thomson Reuters Aranzadi, CGPJ, Instituto de Estudios Europeos de la Universidad de Valladolid, 2015].

Calderón Cuadrado, María Pía, Contra la armonización positiva - y procesalen la Unión Europea, [en Andrés de la Oliva Santos y María Pía Calderón Cuadrado, dirs.: La armonización del Derecho Procesal tras el Tratado de Lisboa, Cizur Menor, Thomson Reuters, Aranzadi, 2012].

Costas Trascasas, Milena, Seguridad nacional y derechos humanos en la reciente jurisprudencia del Tribunal Europeo de Derechos Humanos (TEDH) en materia de terrorismo internacional: ¿hacia un nuevo equilibrio?, [en Elena Conde Pérez y Sara Iglesias Sánchez, coord.: Terrorismo y legalidad internacional, Madrid, Dykinson, 2012].

Forner Delaygua, Joaquín y González Viada, Natacha, La acción de la Unión Europea contra el terrorismo, "Revista de Estudios Europeos", 53 (2009).

Jiménez García,Francisco, Tutelajudicialefectiva, pilaresintergubernamentales de la Unión Europea y Naciones Unidas o viceversa. El periplo comunitario marcado por los asuntos Yusuf/Kadi, Ayadi/Hassan, Modjahedines del pueblo de Irán y Segi/gestoras, [en Antonio Cuerda Riezu y Francisco Jiménez García, dirs.: Nuevos desafíos del Derecho Penal Internacional. Terrorismo, crimenes internacionales y derechos fundamentales, Madrid, Tecnos, 2009].

Jiménez-Villarejo, Francisco, Ejecución en la Unión Europea de las resoluciones que impongan sanciones pecuniarias. Comentarios a la Ley 1/2008, de 4 de diciembre, [en Coral Arangúena Fanego, coord.: Espacio Europeo de Libertad, Seguridad y Justicia, Valladolid, Lex Nova, 2010].

Jimeno Bulnes, Mar, La orden europea de detención y entrega: análisis normativo, [en Coral Arangüena Fanego, Montserrat de Hoyos Sancho y Carmen Rodríguez-Medel Nieto, coords.: Reconocimiento Mutuo de Resoluciones Penales en la Unión Europea, Cizur Menor, Thomson Reuters Aranzadi, CGPJ, Instituto de Estudios Europeos de la Universidad de Valladolid, 2015]. 
Pérez Bernárdez, Carmela, El collage de la politica antiterrorista de la Unión Europea, [en Manuel Pérez González, dir., y Elena Conde Pérez, coord.: Lucha contra el terrorismo, Derecho Internacional Humanitario y Derecho Penal Internacional, Valencia, Tirant lo Blanch, 2012].

Pérez Gil, Julio, Equipos conjuntos de investigación penal, [en Mar Jimeno Bulnes coord.: La cooperación judicial civil y penal en el ámbito de la Unión Europea: instrumentos procesales, Bosch editor, Universidad de Burgos, 2007].

Revenga Sánchez, Miguel, Protección multinivel de los derechos fundamentales y lucha contra el terrorismo a escala europea (a propósito de las listas negras y otras anomalías de la Unión), "Revista vasca de Administración Pública", 82 (2008).

Remotti Carbonell, Carlos, Las medidas contra el terrorismo en el marco del Tratado de Prüm, "Revista de Derecho constitucional europeo", 7 (2007). Tiedemann, Klaus, El futuro del proceso penal europeo. Aspectos de interés, en especial sobre la lucha antiterrorista, [en Juan-Luis Gómez Colomer y José-Luis González Cussac, coords.: Terrorismo y proceso penal acusatorio, Valencia, Tirant lo blanch, Universitat Jaume-I, 2006].

Tinoco Pastrana, Ángel, El embargo preventivo y el aseguramiento de pruebas en los procesos penales en la UE. Novedades tras la Ley 23/2014, de reconocimiento mutuo de resoluciones penales en la Unión Europea y la Directiva 2014/41/CE relativa a la orden europea de investigación en materia penal, "Cuadernos Europeos de Deusto", 52 (2015).

La participación de las asociaciones de víctimas como parte acusadora en el proceso penal y el nuevo Estatuto de la víctima del delito, por el que se transpone la Directiva 2012/29/UE, "Cuadernos de Política Criminal", 115 (2015). 
